\title{
Insomnia due to Organic Factor
}

National Cancer Institute

\section{Source}

National Cancer Institute. Insomnia due to Organic Factor. NCI Thesaurus. Code C35647.

Insomnia as a result of a physiological cause. 